\title{
PREDICTIVE EVALUATION OF MORTALITY AND MORBIDITY IN CASES OF INTRACEREBRAL HAEMORRHAGE BY CT SCAN
}

\author{
Naresh Kumar1, Jyoti Kumar Dinkar² \\ ${ }_{1}^{1}$ Professor and HOD, Department of General Medicine, Indira Gandhi Institute of Medical Sciences, Patna. \\ ${ }^{2}$ Senior Resident, Department of General Medicine, Indira Gandhi Institute of Medical Sciences, Patna.
}

\begin{abstract}
\section{BACKGROUND}

Stroke is the most common life-threatening neurological disease and is the third leading cause of death surpassed only by cancer and heart disease. Those who survive are usually left with permanent disability. Cerebral infarction is responsible for about $80 \%$ of all strokes, primary intracerebral haemorrhage for $10 \%$ and subarachnoid haemorrhage for $5 \%$. These population are similar in all places where they have been reliably assessed by CT scan. Mortality statistics reveal that stroke type with high case fatality are intracerebral haemorrhage and total anterior circulation infarction.

The aim of the current study was to determine the mortality rate and to evaluate the influence of various factors on the mortality of patients with intracerebral haemorrhage.
\end{abstract}

\section{MATERIALS AND METHODS}

This is in-hospital based, cross-sectional descriptive study done on 62 patients in Department of Medicine and Radiology, Patna Medical College and Hospital, Patna. All patients above 14 years of age with features of primary intracerebral haemorrhage on CT scan were included. Patients with haemorrhages due to trauma, aneurysmal rupture, tumour, anticoagulant therapy and haemorrhagic transformation of cerebral infarct were excluded.

\section{RESULTS}

Out of 62 patients, 38 were males and 24 were females. The mean age for lobar and deep haemorrhages were 58.09 and 54.93 years, respectively. The mortality rate in acute stage was $43.54 \%$. Remaining $65.4 \%$ survived till discharge at the end of acute hospitalisation. In present study, the location of intracerebral haemorrhage was lobar in 17.74\%, deep ganglionic (ventricle) in $74.19 \%$, cerebellar in $3.2 \%$ and pontine/midbrain in $4.8 \%$ of the patients.

\section{CONCLUSION}

Factors independently associated with in-hospital mortality were Glasgow Coma Scale (GCS) score ( $\leq 8)$, hypertension, volume of haematoma, intraventricular haematoma and midline shift. Primary intracerebral haemorrhage is one of the common vascular insults with a relatively high rate of mortality and if survived results in multiple disabilities.

\section{KEYWORDS}

Stroke, Intracerebral Haemorrhage, CT Scan, Mortality, Midline Shift, Glasgow Coma Scale Score, Volume of Haematoma.

HOW TO CITE THIS ARTICLE: Kumar N, Dinkar JK. Predictive evaluation of mortality and morbidity in cases of intracerebral haemorrhage by CT scan. J. Evolution Med. Dent. Sci. 2017;6(58):4276-4278, DOI: 10.14260/Jemds/2017/926

\section{BACKGROUND}

A stroke is rapidly developing clinical symptoms and/or signs of focal and at times global loss of cerebral function with symptom lasting more than 24 hours or leading to death with no apparent cause other than that of vascular origin. Stroke is amongst the leading cause of death exceeding only by heart disease and cancer. ${ }^{1}$ With increasing mean population age, stroke will become an even greater medical and social problem. ${ }^{2}$ Depending on the underlying cause, intracerebral haemorrhage is categorised as either primary or secondary. Primary intracerebral haemorrhage accounts for $78-88 \%$ of cases occurring from the spontaneous rupture of small

Financial or Other, Competing Interest: None.

Submission 13-06-2017, Peer Review 08-07-2017,

Acceptance 14-07-2017, Published 20-07-2017.

Corresponding Author:

Dr. Jyoti Kumar Dinkar

Flat-402, Block-A, Ram Raj Apartment,

Brahmasthani Gali, Near IGIMS,

Sheikhpura-800014, Patna, Bihar.

E-mail:drdinkar03@gmail.com

DOI: $10.14260 /$ jemds $/ 2017 / 926$

\section{(c) $(1)(-$}

vessels damaged by chronic hypertension or amyloid angiopathy. ${ }^{2}$

Accurate and early diagnosis may improve morbidity and mortality rate in the future as newer and more effective therapies are instituted. Primary intracerebral haemorrhage and subarachnoid haemorrhage results in highest early cases of fatality and these patients are more likely to be admitted to hospital. ${ }^{3}$ The accurate determination of prognosis in medically treated intracerebral haemorrhage is an essential step. Multivariate analysis using the technique of logistic regression identified three variable, the Glasgow coma scale score, haemorrhage size and intraventricular extension of blood, which were most predictive of prognosis. ${ }^{4,5}$ Advent of CT in 1974 represented dramatic and important breakthrough in Medicine. CT is capable of imaging the specific morphologic appearance of cerebral infarcts and haematomas early enough and with sufficient accuracy to influence the further clinical workup, care and treatment of these patients. 6,7 Stroke results in a wide range of disabilities, making comparison between patients difficult, but the functional consequences can be assessed using Activities of Daily Living (ADL) scores. ${ }^{5}$ The Barthel scale is numerical and scores 10 functions on a scale 0 (fully dependent) to 20 
(independent). In a comparison of three well-documented ADL scores, it was found that the Barthel score have certain advantages including completeness, sensitivity to change, greater familiarity due to more widespread use and suitable for statistical manipulation. There is no adequate published data and reports available, which determine the mortality and morbidity by CT scan in cases of intracerebral haemorrhage. Hence, the present study was conducted to evaluate the mortality and morbidity of cases of intracerebral haemorrhage by CT scan.

\section{MATERIALS AND METHODS}

This in-hospital based cross-sectional descriptive study was done on 62 patients admitted with diagnosis of spontaneous intracerebral haemorrhage on the basis of CT scan in Neurology Unit, Department of Medicine, Patna Medical College and Hospital, Patna. Patients with haemorrhage due to trauma, aneurysmal rupture, tumour, anticoagulants therapy and haemorrhagic transformation of cerebral infarcts were excluded. Detailed history with thorough clinical examination was done. Detailed haematological and biochemical parameters consisting of $\mathrm{CBC}$, blood sugar and serum creatinine were obtained. Neurological status at presentation was measured by Glasgow coma scale score. The patients were scanned using the SOMATOM AR SP in the Department of Radiology, PMCH, Patna. NCCT (noncontrast CT) slices were taken parallel to the canthomeatal line with slice thickness of either $5 \mathrm{~mm}$ or $10 \mathrm{~mm}$. All available CT imaging films were evaluated by consultant radiologist. The goal of the present study was to investigate the mortality rate and to evaluate the effects of demographic data, vascular risk factors, Glasgow coma scale score and neuroimaging features of haematoma on a cohort of 62 consecutive primary intracerebral haemorrhage patients. The morbidity or disability of the patients was assessed by Barthel score. Statistical analysis was performed to correlate the patient's outcome and each prognostic factor using the Chi-square and t-test. A value of $p<0.05$ was considered to be significant. Descriptive statistics was used to summarise the results of the study. Microsoft excel and SPSS was used.

\section{RESULTS}

\begin{tabular}{|c|c|c|}
\hline Outcome & Number & $\%$ \\
\hline Dead & 27 & 43.54 \\
\hline Alive (survival till discharge/recovery) & 35 & 56.45 \\
\hline \multicolumn{2}{|c|}{ Table 1. Observation of Mortality and } \\
Survival of Intracerebral Haemorrhage \\
Cases at the End of Acute Hospitalisation \\
\hline
\end{tabular}

\begin{tabular}{|c|c|c|c|}
\hline Sex & Dead & Alive & Total \\
\hline Male & 16 & 22 & $\mathbf{3 8}$ \\
\hline Female & 11 & 13 & $\mathbf{2 4}$ \\
\hline Total & 27 & 35 & $\mathbf{6 2}$ \\
\hline \multicolumn{3}{|c|}{ Table 2. Sex Distribution in Patients of } \\
Primary Intracerebral Haemorrhage \\
\hline
\end{tabular}

\begin{tabular}{|c|c|c|c|c|c|}
\hline GCS & Dead & $\mathbf{\%}$ & Alive & $\mathbf{\%}$ & Total \\
\hline$<8$ & 23 & 85.1 & 5 & 14.2 & $\mathbf{2 8}$ \\
\hline$>9$ & 4 & 14.8 & 30 & 85.7 & $\mathbf{3 4}$ \\
\hline Total & $\mathbf{2 7}$ & & $\mathbf{3 5}$ & & $\mathbf{6 2}$ \\
\hline
\end{tabular}

Table 3. Observation of Mortality and Survival on the Basis of Glasgow Coma Score of Intracerebral Haemorrhage Patients at the Time of Presentation

\begin{tabular}{|c|c|c|}
\hline Risk Factors & Number & $\mathbf{\%}$ \\
\hline Hypertension & 31 & 50 \\
\hline Diabetes mellitus & 4 & 6.4 \\
\hline Cardiovascular disease & 1 & 1.6 \\
\hline Prior stroke & 4 & 0.4 \\
\hline No risk factor present & 27 & 43.5 \\
\hline
\end{tabular}

Table 4. Association of Risk Factors in Primary

Intracerebral Haemorrhage Patients ( $n=62)$

\begin{tabular}{|c|c|c|c|}
\hline $\begin{array}{c}\text { Haemorrhage } \\
\text { Volume }\end{array}$ & Dead & Alive & Total \\
\hline $0-29 \mathrm{~cm}^{3}$ & $7(25.9 \%)$ & $34(97.1 \%)$ & $\mathbf{4 1}$ \\
\hline $30-60 \mathrm{~cm}^{3}$ & $9(33.3 \%)$ & $1(2.8 \%)$ & $\mathbf{1 0}$ \\
\hline$\geq 60 \mathrm{~cm}^{3}$ & $11(40.74 \%)$ & $0(0)$ & $\mathbf{1 1}$ \\
\hline Total & $\mathbf{2 7}$ & $\mathbf{3 5}$ & $\mathbf{6 2}$ \\
\hline Table 5. Observation of Mortality and Survival \\
on the Basis of Volume of Haemorrhage \\
\hline
\end{tabular}

\begin{tabular}{|c|c|c|c|c|c|}
\hline Midline Shift & Dead & $\mathbf{\%}$ & Alive & $\mathbf{\%}$ & Total \\
\hline$<3 \mathrm{~mm}$ & 3 & 11.1 & 19 & 54.2 & $\mathbf{2 2}$ \\
\hline $3-5 \mathrm{~mm}$ & 3 & 11.1 & 9 & 25.7 & $\mathbf{1 2}$ \\
\hline$>5 \mathrm{~mm}$ & 21 & 77.7 & 7 & 20.0 & $\mathbf{2 8}$ \\
\hline Total & $\mathbf{2 7}$ & & $\mathbf{3 5}$ & & $\mathbf{6 2}$ \\
\hline \multicolumn{6}{|c|}{ Table 6. Observation of Mortality and } \\
Survival of Intracerebral Haemorrhage \\
Patients on the Basis of Midline Shift \\
\hline
\end{tabular}

\begin{tabular}{|c|c|c|}
\hline Barthel Score & $\begin{array}{c}\text { Number of Cases } \\
\text { (Frequency) }\end{array}$ & $\begin{array}{c}\text { Cumulative } \\
\text { Frequency }\end{array}$ \\
\hline 0 & 28 & 28 \\
\hline 2 & 2 & 30 \\
\hline 4 & 2 & 32 \\
\hline 5 & 1 & 33 \\
\hline 8 & 11 & 44 \\
\hline 9 & 1 & 45 \\
\hline 10 & 2 & 47 \\
\hline 13 & 1 & 48 \\
\hline 14 & 1 & 49 \\
\hline 16 & 4 & 53 \\
\hline 17 & 1 & 54 \\
\hline 18 & 3 & 57 \\
\hline 20 & 4 & 61 \\
\hline Not evaluated & 1 & 62 \\
\hline \multicolumn{2}{|c|}{ Table 7. Observation of Morbidity in all } \\
Intracerebral Haemorrhage Patients at the \\
End of Hospital Stay (Day of Discharge/Mortality) \\
\hline
\end{tabular}

Mean Barthel activity of daily living score $=6.16$.

Modal Barthel activity of daily living score $=0$.

Median Barthel activity of daily living score $=4$.

\section{DISCUSSION}

The purpose of this in-hospital based cross-sectional descriptive study was to correlate volume, location of lesion (haemorrhage), Glasgow coma scale score and midline shift with clinical picture and prognosis and to determine clinical and CT parameters or findings that could predict prognosis. Among the 62 patients, 38 (61.2\%) were males and 24 $(38.7 \%)$ were females (sex ratio $=1.5: 1)$. The mean ages for lobar and deep haemorrhages were 58.09 and 54.93 years, respectively. The mortality rate in acute stage was $43.54 \%$ (27 out of 62 cases). Remaining 65.4\% (35 out of 62 cases) survived till discharge at the end of acute hospitalisation. Focal neurological deficit was the commonest presentation observed in $77.4 \%$ of the cases while alteration/loss of 
consciousness was seen in $66.12 \%$ of the cases in current analysis. In the present study, the volume of haematoma ranged from $0.06 \mathrm{~cm}^{3}$ to $177.08 \mathrm{~cm}^{3}$ (mean=32.69 $\mathrm{cm}^{3}$ ). Mean volumes for lobar, deep and pontine/cerebellar haemorrhages were $28.44 \mathrm{~cm}^{3}, 36.52 \mathrm{~cm}^{3}$ and $6.84 \mathrm{~cm}^{3}$, respectively. When haematoma volume exceeded $61 \mathrm{~cm}^{3}(11$ patients) the mortality was $100 \% .^{8}$ Further, it was observed that $82.14 \%$ of the patients in coma (GCS $\leq 8$ ) expired, whereas $11.76 \%$ of the patients with GCS $>9$ died during acute hospitalisation. According to the study, midline shift was another important determinant of prognosis and it has been observed that mortality in patients with midline shift $>5$ mm was 18.7 times more than that in patients with shift $<5$ mm. ${ }^{9,10}$ These figures are strikingly similar with the earlier studies if one considers the differences in time of assessment and the inclusion of posterior fossa haemorrhages. A history of hypertension, which in most cases was under treatment was present in $50 \%$ (31) of the patients and $6.4 \%$ (4) of the patients had a history of prior stroke before the recent incidence of haemorrhagic stroke. In patients who survived the acute stage, the prediction of functional outcome was of great importance, but remained difficult because of methodologic problems including sample selection bias, timing of the initial assessment, criteria for measuring outcome and the role of confounding factors. The present study revealed that mean Barthel score was 6.16 while modal Barthel score was 0 (fully dependent). The rate of recovery of all impairments is maximal in the first few weeks, slows down after two or three months and probably stops at about six to twelve months of post stroke. ${ }^{11}$

\section{CONCLUSION}

CT offers an excellent imaging modality for early detection of intracerebral haemorrhage, which helps to provide early and better management of the patients. In this hospital-based study, 62 patients with spontaneous intracerebral haemorrhage was analysed. According to the analysis, the mortality rate in acute stage was $43.54 \%$. Focal neurologic deficit was the commonest presentation observed in $77.4 \%$ of the cases while alteration/loss of consciousness was seen in $66.12 \%$ of the cases in the present study. Mortality in patients with midline shift $>5 \mathrm{~mm}$ was 18.7 times more than that in patients with shift $\leq 5 \mathrm{~mm}$. Similarly, mortality in patients with Glasgow coma scale score $<8$ was 12.2 times more than that in patients with Glasgow coma scale score $\geq 9$ and the mortality in patients with volume of haematoma $>29 \mathrm{~cm}^{3}$ was
98.5 times more than that in patients with volume of haematoma $<29 \mathrm{~cm} .{ }^{3}$ On the basis of present study, it was evident that those three variables when considered together (midline shift, Glasgow coma scale score and volume of haematoma), the mortality was predicted with a sensitivity of $88.89 \%$ and specificity of $94.3 \%$. The mean Barthel score was 6.16 while modal Barthel score was 0. As the last recorded follow up for most patients included in present study comprised death or discharge after acute hospitalisation, no conclusion could be drawn regarding the functional outcome.

\section{REFERENCES}

[1] Brown MM, Markus H, Oppenheimer S. Stroke medicine. $1^{\text {st }}$ edn. United Kingdom: Taylor \& Francis group 2006.

[2] Edelman RR, Hesselink JR, Zlatkin MB, et al. Clinical magnetic resonance imaging. 3rd edn. Brain intracranial haemorrhage, Saunders 2005:1287-8.

[3] Buensuceso AM. Predictors of mortality based on CT scan findings of patient admitted due to hypertensive intracerebral hemorrhage at the Philippine heart center. Phil Heart Center J 2007;13(2):155-60.

[4] Qureshi AI, Tuhrim S, Broderick JP, et al. Spontaneous intracerebral hemorrhage. $\mathrm{N}$ Engl J Med 2001;344(19):1450-60.

[5] Dixon AA, Holness RO, Howes WJ, et al. Spontaneous intracerebral hemorrhage: an analysis of factors affecting prognosis. Can J Neurol Sci 1985;12(3):267-71.

[6] Wolfe CD, Taub NA, Woodrow EJ, et al. Assessment of scales of disability and handicap for stroke patients. Stroke 1991;22(10):1242-4.

[7] Furlan AJ, Whisnant JP, Elveback LR. The decreasing incidence of primary intracerebral hemorrhage: a population study. Ann Neurol 1979;5(4):367-73.

[8] Agrawal JK, Somani PN, Katiyar BC. A study of risk factor in non-embolic cerebrovascular disease. Neurology India 1976;24(3):125-33.

[9] Bolander HG, Kourtopoulos H, Liliequist B, et al. Treatment of spontaneous intracerebral haemorrhage. A retrospective analysis of 74 consecutive cases with special reference to computer tomographic data. Acta Neurochir 1983;67(1-2):19-28.

[10] Helweg-Larsen S, Sommer W, Strange P, et al. Prognosis for patients treated conservatively for spontaneous intracerebral hematomas. Stroke 1984;15:1045-8.

[11] Adams RD, Sidman RL. Introduction to neuropathology. New York. McGraw-Hill 1968. 